\title{
DIFICULDADE DE APRENDIZAGEM NA DISCIPLINA LÍNGUA INGLESA E SUA RELAÇÃO COM O AMBIENTE FAMILIAR NO COLÉGIO ESTADUAL SÃO VICENTE DE PAULO
}

\section{ARTIGO ORIGINAL}

DUARTE, Solange De Souza ${ }^{1}$

COÊLHO, Márcio Wendel Santana ${ }^{2}$

DUARTE, Solange De Souza. COÊLHO, Márcio Wendel Santana. Dificuldade de aprendizagem na disciplina Língua Inglesa e sua relação com o ambiente familiar no Colégio Estadual São Vicente de Paulo. Revista Científica Multidisciplinar Núcleo do Conhecimento. Ano 05, Ed. 03, Vol. 02, pp. 159-176. Março de 2020. ISSN: 2448-0959,

Link de

acesso: https://www.nucleodoconhecimento.com.br/educacao/disciplina-linguainglesa

\section{RESUMO}

Este estudo tem como discutir, a partir de uma revisão da literatura, sobre a dificuldade de aprendizagem em relação à disciplina de Língua Inglesa ministrada no Colégio Estadual São Vicente de Paulo, em Bom Jesus da Lapa - BA. O objetivo

1 Mestre em Ciencias Educação pela FICS - Faculdad Interamericana de Ciencias Sociales, pós-graduada em Língua Portuguesa pela FACIG - Faculdade Cidade de Guanhães - MG e pós-graduada em Língua Inglesa pela FIJ - Faculdade Integrada de Jacarépaguá - RJ. Graduada em Letras/Inglês pela UNEB - Universidade do Estado da Bahia.

2 Doutor em Ciências da Educação pela U. Autônoma, Doutor em Ciências da Saúde \& Psicanalise Clínica - OPEN e Mestre em Ciências da Educação pela U. AMERICANA, Especialista em Pedagogia Hospitalar - UNISA/SP, Gestão Escolar \& Psicologia Hospitalar, Gr aduado em Pedagogia - UNISA/SP. 
do artigo é verificar quais são as dificuldades de aprendizagem, identificar e relatar os problemas enfrentadas no ensino da língua inglesa e comprovar se os docentes buscam superar as dificuldades de aprendizagem. O presente estudo alinha-se à abordagem quantitativa e qualitativa, pautando-se, para isso, na análise de um estudo de caso. Assim, aplicou-se entrevistas para analisar as dificuldades de aprendizagem e os dados foram coletados a partir das respostas dos professores, dos alunos e da família. Os resultados apontaram que a solução para resolver as dificuldades de aprendizagem na disciplina de língua inglesa é adotar estratégias de leitura e escrita na escola bem como o desenvolvimento de atividades na escola ou em casa buscando caminhos que favorecem a aprendizagem de forma autônoma e crítica para superar as dificuldades.

Palavras-chave: Aprendizagem, dificuldade, língua inglesa, família.

\section{INTRODUÇÃO}

É importante discutirmos, nos dias de hoje, sobre a importância da língua inglesa, que é uma das línguas mais faladas no mundo globalizado, bem como sobre os seus desafios. Nesse contexto, o estudo visa refletir sobre a dificuldade de aprendizagem na disciplina de língua inglesa e sobre o acompanhamento da família nesse processo. Considerou-se o Colégio Estadual São Vicente de Paulo, em Bom Jesus da Lapa $\mathrm{BA}$, visto que está relacionado com as experiências cotidianas da comunidade escolar. O ensino da língua inglesa na escola pública é visto como deficiente e precário pela falta de interesse da maioria dos alunos pela disciplina. Por este motivo, o processo de ensino e aprendizagem desta disciplina tem enfrentado diversas dificuldades.

A pesquisa é relevante pois destaca as principais causas das dificuldades de aprendizagem em língua inglesa. Elas estão as salas de aulas lotadas, aos professores que não tem formação no idioma bem como há a falta de motivação dos alunos pela disciplina. Nesse sentido, o ensino da língua inglesa deve ser mais atrativo para que o interesse e o desejo do aluno para aprender o idioma juntamente com a cultura do país sejam despertados. Dessa forma, o estudo realizou uma pesquisa de 
campo a ser analisado de forma comparativa, sendo a sua abordagem qualitativa e quantitativa para analisar os dados vinculados a pesquisa que poderão contribuir para aplicação de estratégias de aprendizagem beneficiando novas pesquisas da área.

\section{OBJETIVO}

\subsection{OBJETIVO GERAL}

- Verificar as dificuldades de aprendizagem no ensino da língua inglesa e o acompanhamento da família no Colégio São Vicente de Paulo, em Bom Jesus da Lapa - BA.

\subsection{OBJETIVOS ESPECÍFICOS}

- Identificar as dificuldades de aprendizagem no ensino da língua inglesa e como ocorre o acompanhamento da família no contexto do Colégio São Vicente de Paulo, em Bom Jesus da Lapa - BA;

- Relatar quais são as dificuldades enfrentadas no ensino da língua inglesa e como se dá o processo de acompanhamento da família no Colégio São Vicente de Paulo, em Bom Jesus da Lapa - BA;

- Comprovar se os docentes buscam superar as dificuldades de aprendizagem ao ensinar a língua inglesa no colégio São Vicente de Paulo, em Bom Jesus da Lapa - BA.

\section{METODOLOGIA DE PESQUISA}

Essa pesquisa se propõe a realizar um estudo de caso. Trata-se de um método de pesquisa de caráter estruturado, e, dessa forma, pode ser aplicado nas mais diversas áreas a fim de que se compreenda situações distintas dos mais variados fenômenos e/ou problemas sociais (ANDRADE et a, 2017). A partir da análise de um estudo de caso é possível conhecer e refletir sobre fenômenos individuais ou coletivos. Uma vez que se trata de um método de pesquisa, possui características próprias e pode ser conceituado de diferentes formas, a depender da corrente teórica adotada. Yin (2010) 
define o estudo de caso como uma pesquisa empírica que tem como objetivo investigar os fenômenos contemporâneos dentro de um contexto da vida real, aqui, no caso, das dificuldades de aprendizagem no ensino de língua inglesa em um colégio da Bahia.

O estudo de caso, segundo Yin (2010), é utilizado, sobretudo, quando os limites entre o fenômeno e o contexto são pouco evidentes, o que faz com que seja necessário realizar uma investigação mais complexa para se obter respostas para esse problema (como as pesquisas de campo, por exemplo). Devido à essa finalidade, tem-se como objetivo, ao realizar um estudo de caso, explorar, descrever e explicar um determinado evento (no caso dessa pesquisa objetiva-se conhecer e explorar o contexto do colégio escolhido para descrever e explicar as dificuldades de aprendizado e os desafios para se ensinar a língua inglesa no colégio baiano delimitado para este estudo). Tem-se como escopo, ainda, fornecer uma compreensão ampla e detalhada sobre um determinado fenômeno/problema individual ou coletivo (estamos analisando o contexto de um colégio, mas vários outros podem lidar com a mesma realidade).

Stake (2007), por sua vez, entende que o estudo de caso nada mais é do que um sistema delimitado, e, dessa forma, enfatiza que, de maneira simultânea, há dois princípios em ação nessa abordagem metodológica: a unidade e a globalidade do problema. Nesse sentido, os pesquisadores que se propõem a realizar um estudo de caso devem considerar todos os aspectos que possam vir a ser relevantes para compreender, de maneira ampla, um determinado problema a ser investigado. Considera-se um determinado período para que seja possível ter uma visão mais clara e precisa dos fenômenos a partir de uma descrição detalhada dele (ANDRADE et al, 2017). Assim sendo, o estudo de caso enquanto método de pesquisa, para Stake (2007), requer do pesquisador alguns cuidados com alguns processos como o desenho da pesquisa, a explicação dos procedimentos, os pontos fortes e as limitações do estudo.

Considerando esse contexto podemos enfatizar que, de modo geral, esse método é particularmente eficiente quando o pesquisador deseja responder questões relacionadas ao contexto atual de algum fenômeno social. Reflete sobre como ou por 
que um dado fenômeno social funciona. Embora seja um método capaz de produzir evidências com base em técnicas quantitativas e/ou qualitativas de coleta e análise de dados, pode ser aplicado tanto a partir de uma técnica ou como um instrumento ou abordagem. $\mathrm{Na}$ área da educação (caso dessa pesquisa), costuma ser utilizado como uma abordagem didática para problematizar uma situação a fim de aproximar a teoria da prática.

Pode, ainda, realizar uma análise detalhada de um caso individual e explicar os efeitos desse problema/fenômeno social. Diante do exposto, analisamos o estudo de algumas respostas dos professores, dos alunos de $2^{\circ}$ ano e $3^{\circ}$ ano do Ensino Médio e das suas famílias. Pertencem ao Colégio São Vicente de Paulo, localizado em Bom Jesus da Lapa - BA. A entrevista (anexo) aponta as dificuldades de aprendizagem no processo de ensino-aprendizagem dessa escola, e, a partir dessas respostas, temos como objetivo analisar suas impressões, opiniões, pensamentos e posturas. Para isso, partimos da ideia de que:

Entendemos por pesquisa a atividade básica da ciência na sua indagação e construção da realidade. É a pesquisa que alimenta a atividade de ensino e a atualiza frente a realidade do mundo. Portanto, embora seja uma prática teórica, a pesquisa vincula pensamento e ação, ou seja, nada pode ser intelectualmente um problema se não tiver sido, em primeiro lugar, um problema de vida prática. As questões de investigação estão, portanto, relacionadas a interesses e circunstâncias socialmente condicionadas (MINAYO, 2009, p. 16).

Neste trabalho de cunho qualitativo e quantitativo, considerou-se as respostas dos professores de língua inglesa, alunos e famílias desses que estão associados do Colégio São Vicente de Paulo, em Bom Jesus da Lapa - BA. O presente estudo alinha-se a abordagem quantitativa e qualitativa. A pesquisa quantitativa visa medir e quantificar por meio de dados numéricos e, para isso, adotadas os questionários com perguntas de múltipla escolha para facilitar a coleta. A pesquisa qualitativa, por sua vez, é representada, nesse trabalho, pelo estudo de caso, e, assim, os pesquisadores aplicaram as entrevistas para identificar as dificuldades em relação ao aprendizado 
de língua inglesa. A amostra da pesquisa é pequena e os entrevistados forneceram as suas percepções sobre o assunto estudado.

Para Moreira (2002 apud Oliveira 2011), a diferença entre a pesquisa quantitativa e a qualitativa vai além da simples escolha de estratégias de pesquisa e o procedimento de coleta de dados, representando, na verdade, posições epistemológicas. A pesquisa foi baseada na revisão bibliográfica e também realizou uma pesquisa de campo para dar forma ao estudo de caso. Nesse sentido, os procedimentos que fizeram com que os dados, a partir das respostas, fossem gerados foram coletados a partir das percepções dos professores, alunos e, também, das famílias. O período considerado para a aplicação dos instrumentos de pesquisa foi o ano de 2017, mais especificamente o período em que foi dado início aos estudos de recuperação.

\section{ANÁLISE E DISCUSSÃO DE DADOS}

Considerou-se as respostas dos professores, alunos e de sias famílias a respeito da dificuldade de aprendizagem da língua inglesa. A população da pesquisa contemplou 60 alunos, 30 famílias e 03 professores associados ao Colégio São Vicente de Paulo, localizado em Bom Jesus da Lapa - BA. A amostra, por sua vez, considerou as respostas de 03 alunos (sendo 1 aluno do $2^{\circ}$ ano do Ensino Médio e 2 alunos do $3^{\circ}$ ano do Ensino Médio, 02 professores que atuam em ambas as turmas $\left(2^{\circ}\right.$ e $3^{\circ}$ ano do Ensino Médio) e 02 famílias.

A pesquisa compreendeu todo o ano letivo de 2017, sobretudo o período em que foram iniciados os estudos de recuperação, uma vez que demonstrou as dificuldades dos alunos em relação à língua inglesa. Embora tenham sido escolhidos, inicialmente, 60 alunos e 30 famílias, 57 estudantes e 28 famílias não participaram da pesquisa por razões diversas: ausência durante os dias de aplicação, desistências, etc. De acordo com a entrevista $40 \%$ dos alunos entrevistados estavam estudando no $2^{\circ}$ ano do Ensino Médio e $60 \%$ no 3ํano do Ensino Médio. 
Figura 1: Faixa etária dos entrevistados

\section{Qual é a sua idade?}

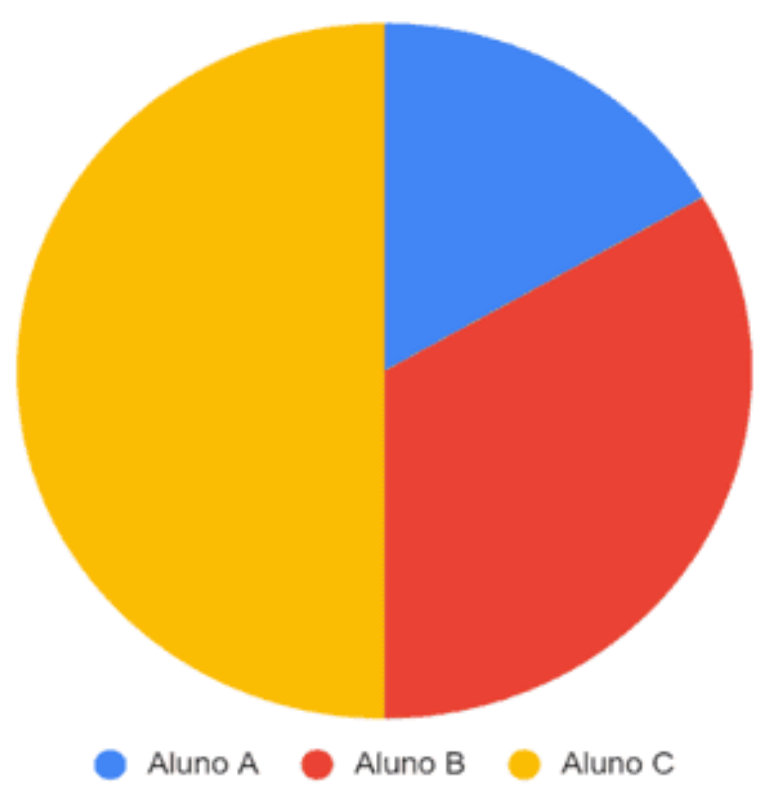

Fonte: Elaborado pelos autores (2017)

Conforme o gráfico, a faixa etária dos estudantes é a de: aluno A: 17 anos (percentual de 16,7\%), aluno B:18 anos (percentual de 33,3\%) e aluno C: 16 anos (percentual de $50 \%$ ). Quando questionados sobre as principais dificuldades de aprendizagem no ensino de língua inglesa, os professores apontaram que:

Qual é a dificuldade de aprendizagem da língua inglesa?

PROFESSORA A: Material didático inapropriado

PROFESSORA B: Na maioria das vezes há o desinteresse por parte dos alunos

Já para os alunos, quando questionados sobre as suas dificuldades em relação à língua inglesa, ressaltaram que: 
Qual são as maiores dificuldade na aprendizagem da língua inglesa?

Aluno A: verbos

Aluno B: verbos

Aluno C: verbos

Por outro lado, a família diz que outras disciplinas do currículo:

Quais são as principais dificuldades que seu filho tem na escola?

FAMÍLIA A: Em língua portuguesa

FAMÍLIA B: Física, química, matemática

Podemos perceber que no ambiente escolar nós podemos ter diversos pontos de vista em relação as principais dificuldades enfrentadas no cotidiano escolar, pois, essas visões, são interdisciplinares. Mendes (2017), frisa, em seu estudo, que é na sala de aula, ou seja, no ambiente escolar de ensino e aprendizagem, que o aluno deve executar mais tarefas de natureza cognitiva, que, por sua vez, precisam de atenção, concentração, processamento, elaboração e integração da informação, raciocínio e resolução de problemas. Destaca-se que:

Ensinar uma língua estrangeira, portanto, implica a inclusão de competência gramatical, competência comunicativa, proficiência na língua, além, é claro na mudança de comportamento e de atitude com relação à própria cultura e as culturas alheias (LIMA, 2009, p. 189).

Nesse contexto, percebemos que o campo do ensino de inglês precisa aperfeiçoar os processos de aprendizagem desenvolvidos durante a aula para que os alunos se sintam mais motivados a aprender uma nova língua, e, consequentemente, a sua cultura também. De acordo com os alunos:

Você faz todas as atividades e trabalhos que o professor passa? 
a) Sim b) Não c) As vezes d) Nunca e) Não tenho tempo

Aluno A: Sim

Aluno B: Sim

Aluno C: Não tenho tempo

Segundo o acompanhamento familiar:

Todos os dias verifica se o filho fez os trabalhos e atividades das aulas?

a) Sim b) Não c) As vezes d) Nunca e) Não tenho tempo

FAMÍLIA A: Sim

FAMÍLIA B: As vezes

Contudo, escola e família, trabalhando juntos, podem realizar atividades que buscam desenvolver as estratégias de compreensão de leitura e escrita bem como podem contribuir para que o conhecimento prévio seja ativado. Oliveira (2015), sobre esse fenômeno, ressalta que:

Um comportamento que se aproxima muito da questão da indisciplina é não fazer as atividades extraclasse. Fazê-las é importante para os alunos internalizarem informações linguísticas. Até os exercícios nos quais o aluno deve copiar sentenças e palavras que parecem tão bobos por não exigirem muito esforço cognitivo, são importantes para a fixação da ortografia.(...) no caso de negligenciarem suas tarefas ( consequências como, por exemplo, demora um longo tempo para assimilar os padrões ortográficos e a estrutura da língua inglesa). Se os alunos são crianças, inevitavelmente o professor deverá convocar a coordenação da escola para que ela converse com os pais a respeito disso (OLIVEIRA, 2015, p. 35). 
A leitura contribui para com o desenvolvimento da aprendizagem da língua inglesa, uma vez que produz sentidos a partir da interação da ideia transmitida pelo texto com o conhecimento que o aluno possui. A modalidade escrita, por sua vez, deve ser vista como uma habilidade a ser desenvolvida.

Figura 2: Quantos livros você costuma ler durante o ano?

\section{Quantos livros você ler durante o ano?}

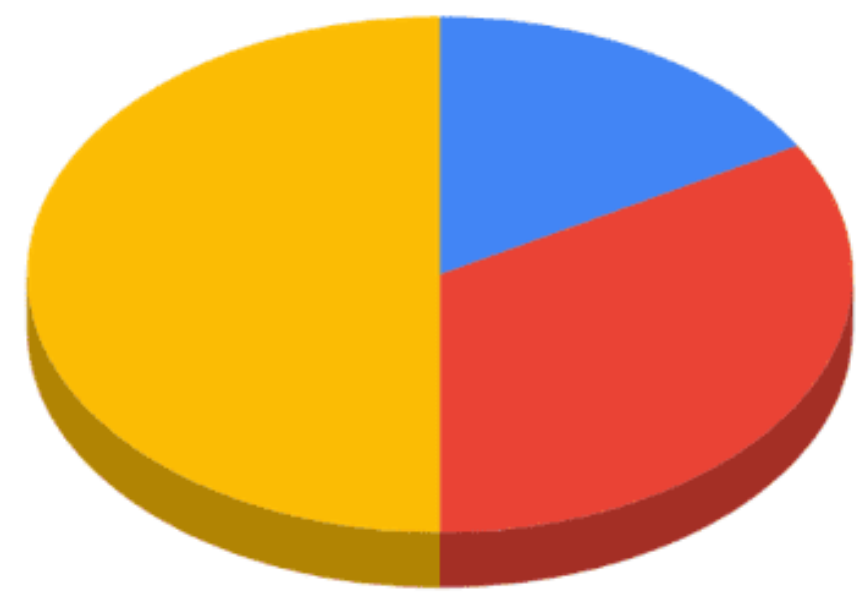

Aluno A

Aluno B

Aluno C

Fonte: Elaborado pelos autores (2017)

Com relação ao número de livros lidos durante o ano letivo, os resultados apontam que o aluno $A$ leu de menos de 5 livros (percentual de 16,7\%), o aluno B leu 4 livros (percentual de $33,3 \%$ ) e o aluno $C$ leu 5 livros (percentual de $50 \%$ ). Mediante a este contexto, algumas questões foram feitas em relação aos hábitos de leitura.

A leitura e a escrita são importantes para você na aprendizagem da língua inglesa? Por que?

Aluno A: Sim, me ajuda no conhecimento e no diálogo 
Aluno B: Sim para melhorar o aprendizado

Aluno C: Sim sem isso não somos nada

Faz algum tipo de incentivo para melhorar a leitura e a escrita?

FAMÍLIA A: Sim

FAMÍLIA B: Sim sempre aconselho e ensino

Observamos, nas falas dos entrevistados, a importância da aprendizagem da língua inglesa bem com da leitura e escrita e como a família tem incentivado o desenvolvimento cognitivo, afetivo e social do aluno, o que oportuniza um bom resultado na aprendizagem. Nesse aspecto, Fragoso (2018) acredita que:

[...] se eu consegui aprender a gostar de fazer exercícios, tenho certeza de que você também pode aprender a gostar de inglês. Comece com atividades que, de alguma forma, sejam prazerosas para você e, aos poucos, introduza aquelas que você não gosta tanto, mas considera necessárias para seu desenvolvimento. E tenha em mente que é melhor fazer pouco, mas com frequência, do que nada. O lema deve ser progresso, não perfeição. Seria bom se pudéssemos tomar uma "pílula do conhecimento" ou uma "pílula do corpo sarado" para atingirmos o nosso objetivo sem termos esforço algum? (FRAGOSO, 2018, p. 25).

A utilização do material didático apropriado nas aulas é fundamental para atrair a atenção desses alunos, porém, para que isso ocorra, o planejamento pedagógico e didático do professor deve prezar pela resolução dos problemas e/ou dificuldades dos educandos.

Quais são os fatores essenciais para o desenvolvimento da capacidade de aprender Inglês?

PROFESSORA A: Formação do professor/material didático apropriado 
PROFESSORA B: Redução do número de alunos por sala/ formação profissionais/material didático apropriado

Em relação a formação de profissionais, pode-se afirmar que:

O grande é dilema para os se dedicam tanto à formação inicial quanto à continuada. $\mathrm{Na}$ inicial, o embate se estabelece com o próprio futuro profissional, que ainda espera ser " ensinado " a usar técnicas que funcionem. Na continuada, o embate costuma surgir no relacionamento com os gestores de instituições privadas e públicas, que ainda esperam resultados claros e diretos, como se a formação consistisse no aprendizado rápido de técnicas (MOITA LOPES, 2013, p. 105).

De acordo com a família, a escola poderia melhorar a aprendizagem de seu filho dessa maneira:

O que a escola poderia fazer para melhorar o ensino / aprendizagem de seu filho?

FAMÍLIA A: Ensinar com atividades e manter os horários de aula sempre a risco

FAMÍLIA B: Ver as dificuldades que eles tem

Afirma Silva (2015), que:

Na prática cotidiana do ensino e aprendizagem, os estilos conflitantes de professor e aluno podem causar as chamadas guerras de estilos em sala de aula (styles wars). Ao terem consciência deste fato, tanto os professores podem prestar atenção aos estilos de seus alunos, procurando atendê-los ou ainda ensiná-los a explorarem melhor seus estilos, aprendendo a transformar informações recebidas em um estilo (o do professor) para outro estilo ( o seu próprio). Assim, um aluno visual pode ser ensinado a tomar notas de uma aula explanada por um 
professor auditivo que apenas discorre a respeito do tema sem usar imagens ou, até mesmo, sem escrever no quadro. Essas anotações do aluno podem conter cores, uso espacial diferenciado com esquemas, mapas semânticos e outros recursos (SILVA, 2015, p. 70).

Portanto, o processo de ensino aprendizagem de língua estrangeira deve receber o apoio de toda a comunidade escolar a respeito de sua importância para melhorar a prática pedagógica. Nas palavras de Rajagopalan (2003):

É por este motivo que, no caso das línguas estrangeiras, sempre se fixou como meta os esforços didáticos nada mais nada menos que a aquisição de uma competência perfeita, entendendo-se por competência perfeita o domínio que o falante nativo supostamente possui da sua língua. Aliás, a partir da chamada revolução chomskiana na linguística, tornou-se redundante qualificar a competência como perfeita. $O$ falante nativo sabe a sua língua e pronto. De acordo com essa cartilha, cabe ao aprendiz de língua estrangeira fazer o possível para se aproximar da competência do nativo (Rajagopalan, 2003, p. 67).

Considerando o contexto apresentado, um novo questionamento foi feito:

Qual a importância do ensino aprendizagem de Língua Inglesa?

PROFESSORA A: Interagir melhor com os meios de comunicação e com o mundo

PROFESSORA B: A aprendizagem de uma segunda língua é muito importante para o desenvolvimento intelectual dos educandos, pois oportuniza os mesmos a conhecer e se conectar com os outras culturas

O aprimoramento do desenvolvimento do processo de ensino-aprendizagem é necessário para que os professores sejam capazes de superar as dificuldades cotidianas e melhorar, dessa forma, o desempenho dos alunos, para isso, fazer uso 
de recursos didáticos atrativos e diferentes é essencial para despertar a atenção desses discentes. A escola, por sua vez, desempenha um papel de suma importância nesse processo, tão importante como a família e o professor. Nesse sentido, a família, a escola e o professor terão melhores resultados diante das dificuldades apresentadas pelo aluno se todos trabalharem juntos. Conforme Scheyerl (2009, p. 126 apud Perin 2005, 150):

Apesar de reconhecerem a importância de se saber inglês, os alunos tratam o ensino de língua inglesa na escola pública ora com desprezo ora com indiferença, o que causa, na maioria das vezes, a indisciplina nas salas de aula [...]. O professor trabalha com a sensação do aluno que não crê no que aprende demonstrando [...]. menosprezo pelo que o professor se propõe a fazer durante a aula.

Segundo Canedo (2018), a família pode, ainda, ser definida pelas funções sociais que se espera que ela cumpra, incluindo a socialização, a proteção das crianças, o apoio e a regulação do comportamento social. Sem o apoio da família no processo escolar do aluno, o risco que ele corre é bem maior, pois estes problemas que, a princípio, são apenas escolares, poderão ter reflexo na vida como um todo. Se a família, a escola e o professor não estiverem trabalhando juntos, não obterão melhores resultados diante das dificuldades apresentadas pelo aluno. Dentro desse contexto, as famílias entrevistadas afirmaram que a função da família era andar sempre de mãos dadas com a escola ajudando a ensinar e incentivar os alunos.

Por fim, as famílias disseram que é tarefa da escola dar continuidade à formação de um bom cidadão e acreditam que ela deve ensinar e ajudar esse aluno a ter uma boa educação. Portanto, a parceria da família com a escola será essencial para o sucesso da educação e todos estudantes. O objetivo é conduzir os alunos para um futuro melhor a partir da construção de objetivos capazes de proporcionar experiências de aprendizagem capazes de construir cidadãos mais críticos. 


\section{CONSIDERAÇÕES FINAIS}

O trabalho teve como objetivo verificar as dificuldades de aprendizagem em língua inglesa bem como refletiu sobre o acompanhamento familiar das dificuldades dos alunos do Colégio Estadual São Vicente de Paulo, localizado em Bom Jesus da Lapa - BA. Constatou-se que existem problemas, mas podem ser superados com o apoio de todos os envolvidos no processo de desenvolvimento das habilidades dos estudantes, promovendo, então, uma aprendizagem melhor, pois com o apoio da comunidade escolar como um todo bem como das famílias os estudantes se sentirão mais dispostos a enfrentar os desafios associados ao aprendizado de uma língua estrangeira.

Considerando o contexto apresentado da escola, o artigo apresentou as principais dificuldades de aprendizagem que foram citadas pelos agentes envolvidos no estudo. A fim de realizar a discussão, foram consideradas as respostas obtidas a partir das entrevistas, e, a partir delas, observou-se, também, que é preciso resolver as dificuldades de aprendizado apontadas pelos professores, alunos e as suas respectivas família por meio de estratégias de ensino, como, por exemplo, o desenvolvimento de atividades de leitura e escrita na escola ou em casa. Consideramos, portanto, a comprovação de que há a interação entre professores, alunos e famílias e que esses, juntos, estão buscando caminhos que favorecem a aprendizagem de forma autônoma e crítica para superar os desafios do cotidiano escolar.

\section{REFERÊNCIAS}

ANDRADE, S. R. de. et al. O estudo de caso como método de pesquisa em enfermagem: uma revisão integrativa. Texto \& Contexto-Enfermagem, v. 26, n. 4, 2017.

CANEDO, M. L. Família e Escola Interações Densas e Tensas. 1.ed. Curitiba- PR: Appris, 2018. 
FRAGOSO, C. Sou péssimo em inglês: tudo o que você precisa saber para alvancar de vez seu aprendizado. 1.ed. Rio de Janeiro: Harper Collins, 2018.

MENDES, M. S. Motivação no ensino médio: orientação dos alunos pelas metas de realização. 1.ed. Curitiba- PR: Appris, 2017.

MILLER, I. K. de. Formação de professores de línguas: da deficiêcia à refleção e ética. In: MOITA LOPES, L. P (Org.). Linguística aplicada na modernidade recente. 1. ed. São Paulo: Parábola Editorial, 2013.

MINAYO, M. C. de. S (org.). Pesquisa Social. Teoria, método e criatividade. 28. ed. Petrópolis, RJ: Vozes, 2009.

OLIVEIRA, L. A. Aula de inglês: do planejamento à avaliação. 1.ed. São Paulo: Parábola Editorial, 2015.

OLIVEIRA, M. F. de. Metodologia científica: um manual para a realização de pesquisas em Administração.Catalão, GO: Universidade Federal de Goiás, 2011.

RAJAGOPALAN, K. Por uma linguística crítica: linguagem, identidade e a questão ética. São Paulo: Parábola Editorial, 2003.

SCHEYERL, D. Ensinar a língua estrangeira em escolas públicas noturnas. In: LIMA, D. C. de (org). Ensino Aprendizagem de língua inglesa: conversa com Especialistas. São Paulo: Parábola Editorial, 2009.

SILVA, W. M. E. A base de apoio à aprendizagem autônoma como um ambiente propiciador de construção de novos conhecimentos. In: RAMOS, R. de. C. G; DAMIÃO, S. M; CASTRO, S. T. R. de. (org). Experiencias didáticas no ensinoaprendizagem de língua inglesa em contextos diversos. São Paulo: Mercado de Letras, 2015.

STAKE, R. E. Investigación com estúdio de casos. 4. ed. Madri, Espanha: Ediciones Morata, 2007. 
YIN, R. K. Estudo de caso: planejamento e métodos. 4. ed. Porto Alegre, RS: Bookman, 2010.

\section{ANEXOS}

\section{ENTREVISTA: ALUNO}

1- Qual é a sua idade?

Aluno A :17 anos

Aluno B :18 anos

Aluno C: 16 anos

2- Qual série você estuda?

Aluno $A: 3$ ano

Aluno B: 3 ano

Aluno C: 2 ano

3- Quantos livros você ler durante o ano?

Aluno A: 4 a 5 livros

Aluno B :4 livros

Aluno C :5 livros

4- Qual são as maiores dificuldade na aprendizagem da língua inglesa?

Aluno A: verbos

Aluno B :verbos 
Aluno C :verbos

5- Quantas horas você estuda por dia?

Aluno A: 7 horas

Aluno $B: 7$ horas

Aluno $\mathrm{C}: 1$ hora

6- Você faz todas as atividades e trabalhos que o professor passa?

1. a) Sim b) Não c) As vezes d) Nunca e) Não tenho tempo

Aluno A: sim

Aluno B: sim

Aluno C: Não tenho tempo

7- A leitura e a escrita são importantes para você na aprendizagem da língua inglesa?

Porque?

Aluno A: sim, me ajuda no conhecimento e no diálogo

Aluno B: sim para melhorar o aprendizado

Aluno C: sim sem isso não somos nada

\section{ENTREVISTA: FAMÍLIA}

1-Qual o nível de escolaridade?

FAMÍLIA A: $2^{\circ}$ - grau completo

FAMÍLIA B: já terminei os estudos

2-Qual é a função da família? 
FAMÍLIA A: andar sempre de mãos dadas com a escola.

FAMÍLIA B: é ensinar e incentivar.

3-O que é tarefa da escola?

FAMÍLIA A: Dá continuidade a formação de um bom cidadão.

FAMÍLIA B: é ensinar e ajudar a ter boa educação.

4- Faz algum tipo de incentivo para melhorar a leitura e a escrita?

FAMÍLIA A: Sim

FAMÍLIA B: Sim sempre aconselho e ensino.

5- Todos os dias verifica se o filho fez os trabalhos e atividades das aulas?

1. a) Sim b) Não c) As vezes d) Nunca e) Não tenho tempo

FAMÍLIA A: Sim

FAMÍLIA B: As vezes

6- Quais são as principais dificuldades que seu filho tem na escola?

FAMÍLIA A: Em língua portuguesa.

FAMÍLIA B: Física, química, matemática.

7- O que a escola poderia fazer para melhorar o ensino / aprendizagem de seu filho?

FAMÍLIA A: Ensinar com atividades e manter os horários de aula sempre a risco.

FAMÍLIA B: Ver as dificuldades que eles tem. 


\section{ENTREVISTA:PROFESSORA}

1-Qual é a dificuldade de aprendizagem da língua inglesa?

PROFESSORA : A material didático apropriado

PROFESSORA : B na maioria das vezes desinteresse por parte dos alunos

2-Quais são as principais causas das dificuldades de no ensino/aprendizagem da língua inglesa dos alunos?

PROFESSORA A: material didático apropriado/ formação do professor

PROFESSORA B: salas de aulas superlotadas e desinteresse na aquisição de um novo idioma por parte dos educandos, além dos educandos além da falta de capacitação dos profissionais.

3-O que a escola tem feito para melhorar a aprendizagem dos alunos com dificuldade na aprendizagem?

PROFESSORA A: projeto de leitura e escrita.

PROFESSORA B: a escola faz parte de um sistema defasado, mas tem elaborado alguns projetos para incentivar o ensino aprendizagem.

4- Existe para você tratamento para as dificuldades na leitura e na escrita em Língua Inglesa? ( ) sim ( ) não

Se existe explique de que forma.

PROFESSORA A: sim

PROFESSORA B: diminuir o número de alunos por sala, capacitar os profissionais da área, disponibilizar recursos didáticos. 
5- Os modelos tradicionais do ensino, que mantêm distantes professores e alunos, estão mudando? Dê sua opinião.

PROFESSORA A: sim. Há uma maior interação entre professores e alunos.

PROFESSORA B: acredito que já tem um bom tempo que a relação professor /aluno tem sofrido grandes mudanças.

6- Quais são os fatores essenciais para o desenvolvimento da capacidade de aprender Inglês?

PROFESSORA : A: formação do professor/ material didático apropriado.

PROFESSORA : B :redução do número de alunos por sala/ formação profissionais / material didático apropriado.

7-Qual a importância do ensino aprendizagem de Língua Inglesa?

PROFESSORA A: interagir melhor com os meios de comunicação e com o mundo

PROFESSORA B: a aprendizagem de uma segunda língua é muito importante para o desenvolvimento intelectual dos educandos, pois oportuniza os mesmos a conhecer e se conectar com os outras culturas.

Enviado: Agosto, 2019.

Aprovado: Março, 2020. 